Article

\title{
$\alpha$-Linolenic Acid-Enriched Cold-Pressed Perilla Oil Suppress High-Fat Diet-Induced Hepatic Steatosis through Amelioration of the ER Stress-Mediated Autophagy
}

\author{
Su Ji Bae ${ }^{1}$, Ji Eun Kim ${ }^{1}$, Hyeon Jun Choi ${ }^{1}$, Yun Ju Choi ${ }^{1}$, Su Jin Lee ${ }^{1}$, Jeong Eun Gong ${ }^{1}$, \\ Sungbaek Seo ${ }^{1}$, Seung Yun Yang ${ }^{1}$, Beum-Soo An ${ }^{1}{ }^{1}$, Hee Seob Lee ${ }^{2}$, Dong Seob Kim ${ }^{3}$, \\ Chung Yeoul Lee ${ }^{4}$ and Dae Youn Hwang $1, * \mathbb{D}$ \\ 1 Department of Biomaterials Science, College of Natural Resources and Life Science/Laboratory Animal \\ Resources Center, Pusan National University, Miryang 50463, Korea; sujibaebae@pusan.ac.kr (S.J.B.); \\ prettyjiunx@naver.com (J.E.K.); rudwns546@naver.com (H.J.C.); poiu335@naver.com (Y.J.C.); \\ nuit4510@naver.com (S.J.L.); kos93589@naver.com (J.E.G.); sbseo81@pusan.ac.kr (S.S.); \\ syang@pusan.ac.kr (S.Y.Y.); anbs@pusan.ac.kr (B.-S.A.) \\ 2 Department of Food Science and Nutrition, College of Human Ecology, Pusan National University, \\ Busan 46241, Korea; heeseoblee@pusan.ac.kr \\ 3 Department of Food Engineering, College of Natural Resources and Life Science, Pusan National University, \\ Miryang 50463, Korea; kds@pusan.ac.kr \\ 4 Gangrim Organics, Miryang 50463, Korea; lcy9@hanmail.net \\ * Correspondence: dyhwang@pusan.ac.kr; Tel.: +82-55-350-5388
}

Academic Editor: Gabriela Rapeanu

Received: 24 April 2020; Accepted: 3 June 2020; Published: 8 June 2020

\begin{abstract}
Perilla oil has been considered to have excellent potential for treating various diseases due to its contents of beneficial fatty acids, such as $\alpha$-linolenic acid, oleic acid and linoleic acid. The therapeutic effects and molecular mechanism of an $\alpha$-linolenic acid-enriched cold-pressed perilla oil (LEP) on hepatic steatosis of an obesity model were investigated by analyzing alterations in fat accumulation and endoplasmic reticulum (ER) stress-mediated autophagy, in high-fat diet (HFD)-induced obesity C57BL/6N mice treated with LEP for 16 weeks. Although no significant alterations were detected in body weight and most organ weights, the liver weight and accumulation of lipid droplets in the liver section were significantly lower in HFD + LEP treated group as compared to the HFD + Vehicle treated group. Reduced mRNA expression levels of adipogenesis and lipogenesis regulating factors, including the peroxisome proliferator-activated receptor $(\mathrm{PPAR})_{\gamma}, \mathrm{CCAAT} /$ enhancer-binding protein $(\mathrm{C} / \mathrm{EBP}) \alpha$, fatty acid synthase (FAS), and adipocyte fatty acid-binding protein 2 (aP2) were observed after LEP treatment for 16 weeks, while the levels of lipolysis were remarkably increased in the same group. Moreover, the LEP-treated groups showed suppression of ER stress-regulating factors, such as the C/EBP homologous protein (CHOP), eukaryotic translation initiation factor $2 \alpha(\mathrm{eIF} 2 \alpha)$, inositol-requiring protein 1 (IRE1) $\alpha$, and Jun-N-terminal kinase (JNK) during anti-hepatic steatosis effects. The expression level of the microtubule-associated protein 1A/1B-light chain 3 (LC3) protein and phosphatidylinositol-3-kinase (PI3K)/AKT/ mammalian target of rapamycin (mTOR) pathway for the autophagy response showed a significant decrease in the HFD+LEP-treated group. Furthermore, ER stress-mediated autophagy was accompanied with enhanced phosphorylation of extracellular signal-regulated kinase (ERK), JNK, and p38 protein in the mitogen-activated protein (MAP) kinase signaling pathway. Taken together, the results of the present study indicate that treatment with LEP inhibits hepatic steatosis in the HFD-induced obese model through regulation of adipogenesis and lipolysis. We believe our results are the first to show that the anti-hepatic steatosis activity of $\alpha$-linolenic acid from cold-pressed perilla oil might be tightly correlated with the amelioration of ER stress-mediated autophagy.
\end{abstract}


Keywords: obesity; cold-pressed perilla oil; linolenic acid; hepatic steatosis; ER stress; autophagy

\section{Introduction}

One of nonalcoholic fatty liver disease (NAFLD) is accompanied by intracellular accumulation of lipid droplets in the liver as hepatic steatosis [1]. This disease effectively progresses to various liver disorders, including nonalcoholic steatohepatitis (NASH), fibrosis, cirrhosis, and hepatocellular carcinoma [1,2]. At the same time, hepatic steatosis increases the risk for the development of type II diabetes, insulin resistance, hypertension, and obesity-related mortality [3,4]. Several previous studies on steatosis in the liver tissue of NAFLD, genetic, and diet-induced obesity (DIO) models show scientific evidence correlating hepatic steatosis and ER stress [5,6]. ER stress-mediated hepatic steatosis and lipogenesis were especially detected in the tunicamycin injected model, ob/ob mice, and the HFD-induced model [6-10]. A positive feedback loop between ER stress and hepatic steatosis is considered as one of the causes for serious liver injury [11]. Also, autophagy is a well-known lysosomal degradative pathway that stimulates cell survival through the regulation of energy supplements or defective organelle elimination during injury conditions [12]. This pathway is linked to the reduction of intracellular lipid droplets, attenuation of inflammation, and improvement of hepatic injury in NAFLD [13]. However, the role and mechanism of ER stress-mediated autophagy in hepatic steatosis remains unclear, although many studies have shown evidence for the interplay between ER stress and inflammation in the pathogenesis of hepatic steatosis [14,15].

Perilla seeds and its oil have garnered great attention for providing health benefits due to their various medicinal properties and phytochemical contents. Perilla seeds are rich in numerous phenolic compounds, including rosmarinic acid, rosmarinic acid-3-O- glucoside, caffeic acid, ferulic acid, and caffeic acid-3-O-glucoside, as well as several flavonoids such as apigenin, luteolin, and catechin [16]. However, the perilla oil extracted from seeds majorly consist of $\alpha$-linolenic acid (C18:3), linoleic acid (C18:2), palmitic acid (C16:1), oleic acid (C18:1), and stearic acid (C18:0). Among these, $\alpha$-linolenic acid is a polyunsaturated fatty acid (PUFA) and considered as one member of omega- 3 fatty acid group that have first double bonds between the third and fourth carbon $[17,18]$. This compound was firstly isolated from linseed oil in 1844 and the exact structure was verified in 1939 [18,19]. Also, $\alpha$-linolenic acid majorly contributes to the reduction of inflammation and the prevention of some chronic diseases through the the inhibition of prostaglandin synthesis [20]. Based on the bioactive components of perilla oil, many significant pharmacological effects were investigated in cancer, diabetes, asthma, microbial infectious disease, inflammation, oxidative stress-related disease, constipation, cognitive impairment, and cardiovascular disease [21-24]. The anti-obesity effects of perilla oil were also verified in some obesity animal models. It was reported that the treatment with perilla oil containing $58 \% \alpha$-linolenic acid decreased the serum level of triglycerides (TG) and the weight of white adipose tissue, without altering the food intake and bodyweight of animals [25]. Administration of perilla oil-rich diet for 16 weeks ameliorated the HFD-induced hepatic steatosis and prevented an increase of TG, total cholesterol (TC), and low-density lipoprotein-cholesterol (LDL-C) levels in serum [26,27]. A similar anti-obesity effect was detected in the HFD-induced obesity model treated with $200 \mathrm{mg} / \mathrm{kg}$ and $1000 \mathrm{mg} / \mathrm{kg}$ of perilla oil for 12 weeks [28]. However, no studies provide any scientific evidence of the beneficial effects of LEP on ER stress-mediated autophagy during anti-hepatic steatosis effects, even though the outcome of the LEP-enriched western-style diet was focused on the inhibition of the lipid profile and hepatic steatosis [27].

This study was, therefore, undertaken to investigate the therapeutic responses and mechanisms during the anti-hepatic steatosis effects of LEP in an HFD-induced obesity model, and evaluate the possibility of developing cold-pressed perilla oil as a new natural medicine. Our results provide the first scientific evidence in the obesity model, that the inhibitory effects of $\alpha$-linolenic acid on hepatic steatosis are associated with ER stress-mediated autophagy. 


\section{Results}

\subsection{Determination of $\alpha$-Linolenic Acid Concentration in LEP}

The LEP composition was analyzed using Gas Chromatography-Mass Spectrometry (GC-MS). Five major fatty acids were detected in LEP, including $\alpha$-linolenic acid, oleic acid, linoleic acid, palmitic acid, and stearic acid. The highest concentration of fatty acid was determined to be $\alpha$-linolenic acid $(65.03 \%)$, followed by oleic acid (15.37\%), linoleic acid (12.11\%), palmitic acid (4.95\%), and stearic acid $(2.35 \%)$ (Figure $1 \mathrm{~A})$. These results indicate the potential of LEP for treating HFD-induced hepatic steatosis.
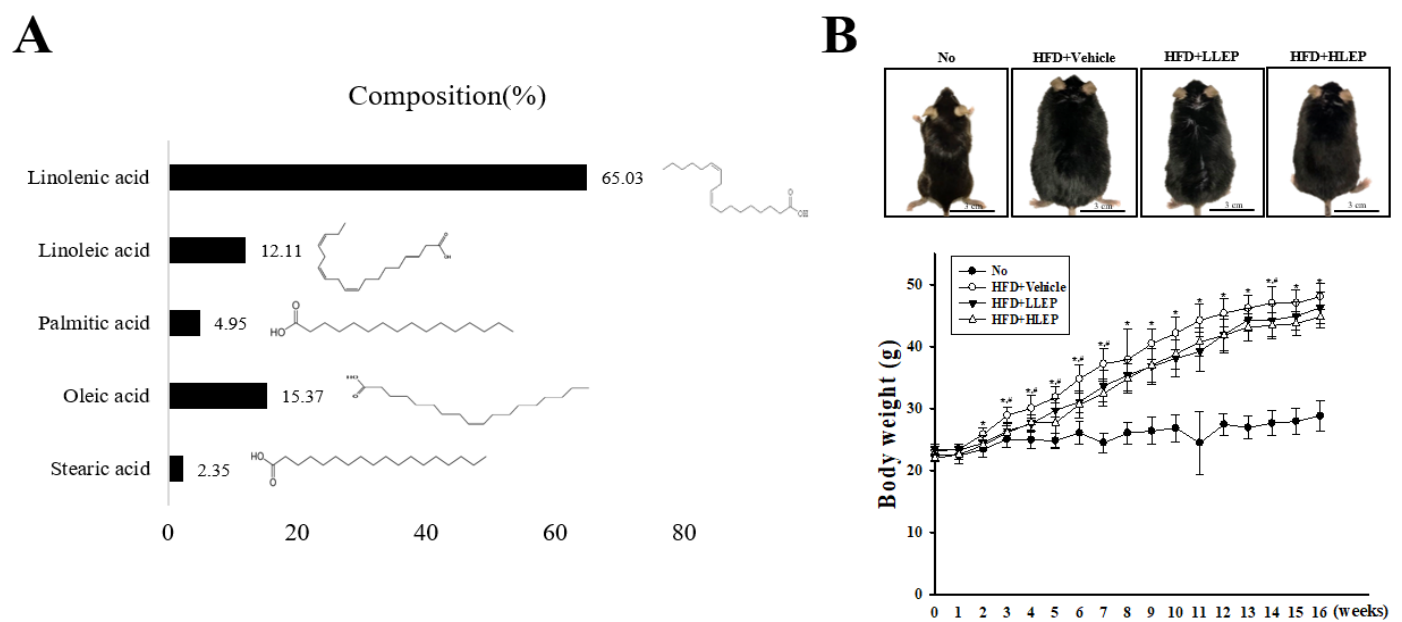

Figure 1. Composition of LEP and assessment of bodyweight. (A) GC-MS analysis of LEP contents revealed five fatty acids-linoleic acid, $\alpha$-linolenic acid, stearic acid, oleic acid, and palmitic acid. (B) The bodyweight of No, HFD + Vehicle, HFD + LLEP-, and HFD + HLEP-treated groups were measured from 0 to 16 weeks, using a chemical balance. Five to seven mice per group were used in the bodyweight measurements. Data represent the mean \pm SD. ${ }^{*} p<0.05$ compared to the No treated group. \# $p<0.05$ compared to the HFD + Vehicle-treated group. Abbreviations: HFD, high-fat diet; LLEP, low concentration of LEP; HLEP, high concentration of LEP.

\subsection{Suppressive Effects of LEP on Bodyweight and Serum Lipid Profile of HFD-Induced Obesity Mice}

We measured the alterations in bodyweight, and serum lipid profile of HFD + LEP-treated mice to investigate the suppressive effects of LEP against obesity. As presented in Figure 1B, the bodyweights remarkably increased in the HFD-feeding group as compared to the No group. However, decreased bodyweights were detected in the HFD + LEP treated groups, although there was no significance at the several time points evaluated. A similar decrease was observed in the lipid profile factors of the HFD + LEP treated groups. Especially, the serum concentrations of TC, LDL-C, and glucose (GLU) were lower in the HFD + LEP-treated groups than the HFD + Vehicle treated group, although other factors evaluated remained constant (Table 1). The results of the present study suggest that LEP treatment for 16 weeks suppresses the bodyweight gain, as well as increases the concentrations of TC, LDL-C, and GLU in serum. 
Table 1. Concentration of TC, TG, LDL-C, HDL-C, and GLU in serum.

\begin{tabular}{ccccc}
\hline \multirow{2}{*}{ Factors } & No & Vehicle & HFD & \multirow{2}{*}{ HLEP } \\
\cline { 4 - 5 } & & & LLEP & \\
\hline TC $(\mathrm{g} / \mathrm{dL})$ & $83.8 \pm 6.0$ & $190.7 \pm 10.9^{*}$ & $152.7 \pm 34.0^{*}, \#$ & $145.3 \pm 24.9 *, \#$ \\
\hline TG $(\mathrm{mg} / \mathrm{dL})$ & $55.4 \pm 10.1$ & $61.7 \pm 9.2$ & $49.7 \pm 14.9$ & $49.5 \pm 14.0$ \\
\hline LDL-C $(\mathrm{mg} / \mathrm{dL})$ & $9.3 \pm 2.4$ & $35.0 \pm 6.7^{*}$ & $32.6 \pm 4.6^{*}$ & $21.8 \pm 5.0^{*, \#}$ \\
\hline HDL-C $(\mathrm{mg} / \mathrm{dL})$ & $74.6 \pm 5.2$ & $141.2 \pm 5.9^{*}$ & $144.2 \pm 13.3^{*}$ & $148.5 \pm 14.5^{*}$ \\
\hline GLU $(\mathrm{mg} / \mathrm{dL})$ & $254.8 \pm 41.1$ & $448.6 \pm 77.3^{*}$ & $415.25 \pm 43.8^{*}$ & $352.2 \pm 68.3^{*}$ \\
\hline
\end{tabular}

Five to six mice per group were used for the preparation of serum, and the biochemical analyses were assayed in duplicate for each sample. Data represent the mean $\pm \mathrm{SD} .{ }^{*} p<0.05$ compared to the No-treated group. ${ }^{\#} p<0.05$ compared to the HFD + Vehicle-treated group. Abbreviations: HFD, high-fat diet; LLEP, low concentration of LEP; HLEP, high concentration of LEP.

\subsection{Inhibitory Effect of LEP on Fat Accumulation in Abdominal Fat Tissue}

We further investigated whether LEP treatment for 16 weeks inhibits fat accumulation in abdominal fat tissue. To achieve this, the weight of abdominal fat and the average area of each adipocyte were measured in the HFD + LEP-treated mice. The decreased weight gains of abdominal fat in the HFD feeding group was not observed in the LLEP or HLEP-treated groups (Figure 2A). However, a remarkable decrease was detected in the average area of each adipocyte in hematoxylin and eosin (H\&E) stained fat tissue. These levels were significantly and dose-dependently decreased in the HFD + LLEP- and HFD + HLEP-treated groups, as compared to the HFD + Vehicle-treated group (Figure 2B). These results indicate that LEP treatment inhibits the accumulation of abdominal fat tissue in HFD-induced obesity mice.
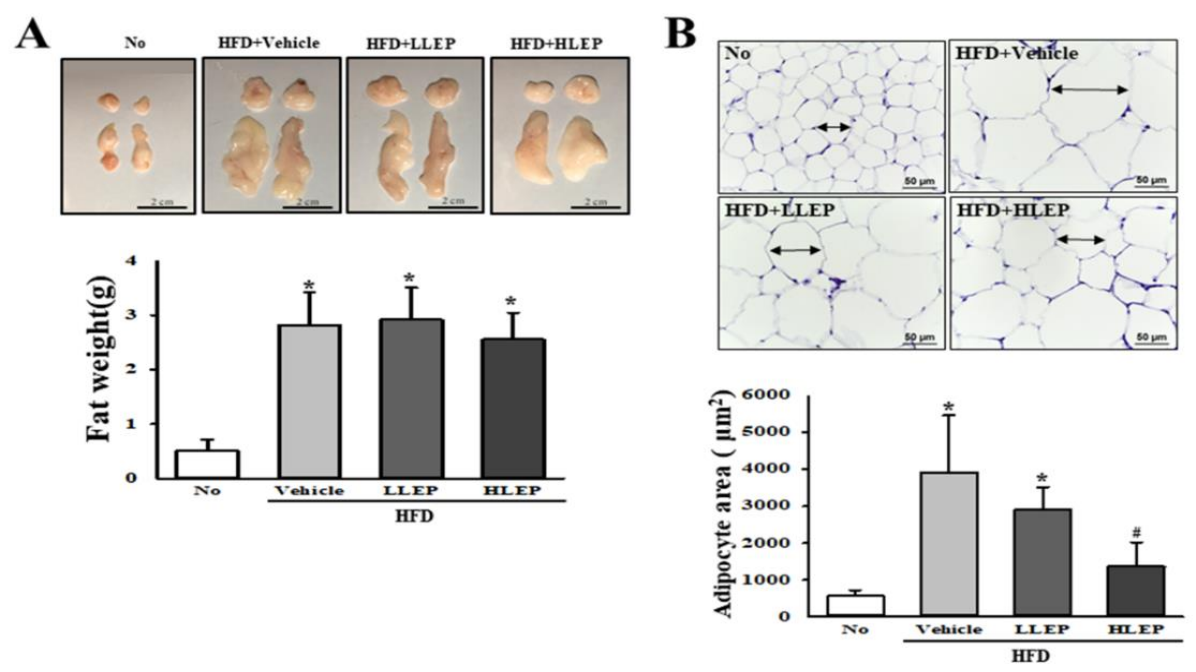

Figure 2. Measurement of fat weight and average area of adipocytes. (A) The fat weight is presented by combining the weight of the epididymis and retroperitoneal fat. In the fat image, the upper part indicates the retroperitoneal fat, and the lower part indicates the epididymis fat harvested from the abdominal region of mice of all subset groups. Five to six mice per group were used for the collection of fat tissues; the weight of fat tissue was measured in duplicate for each tissue. (B) After taking a photo of the fat tissue at $200 \times$ magnification, and the area of each adipocyte was measured using the Image J program. The average area of each adipocyte is also presented as graphs. Five to six mice per group were used for the preparation of H\&E stained tissues; the area of adipocytes was measured in duplicate for each slide. Data represent the mean \pm SD. ${ }^{*} p<0.05$ compared to the No-treated group. $\# p<0.05$ compared to the HFD + Vehicle-treated group. Abbreviations: HFD, high-fat diet; LLEP, low concentration of LEP; HLEP, high concentration of LEP. 


\subsection{Inhibitory Effect of LEP on Hepatic Steatosis in Liver Tissue}

To investigate whether LEP treatment for 16 weeks inhibits hepatic steatosis in liver tissue, the weight and fat accumulation of liver were measured in the HFD-induced obesity model after LEP consumption. The weight of the liver was observed to be heavier in the HFD feeding group than those in the No treated group. However, these levels were not decreased in the HFD + LLEP- and HFD + HLEP-treated groups, as compared to the HFD + Vehicle-treated group (Figure 3A). A significant decrease pattern was observed in the average number of lipid droplets in liver tissue. Liver sections of the HFD + Vehicle-treated group showed dramatic increase in the number of lipid droplets compared to the No-treated group. In comparison, the number of lipid drops was decreased in the HFD + LLEPand HFD + HLEP-treated groups (Figure 3B). These results indicate the capability of LEP to inhibit hepatic steatosis of liver tissue in HFD-induced obesity mice.

A
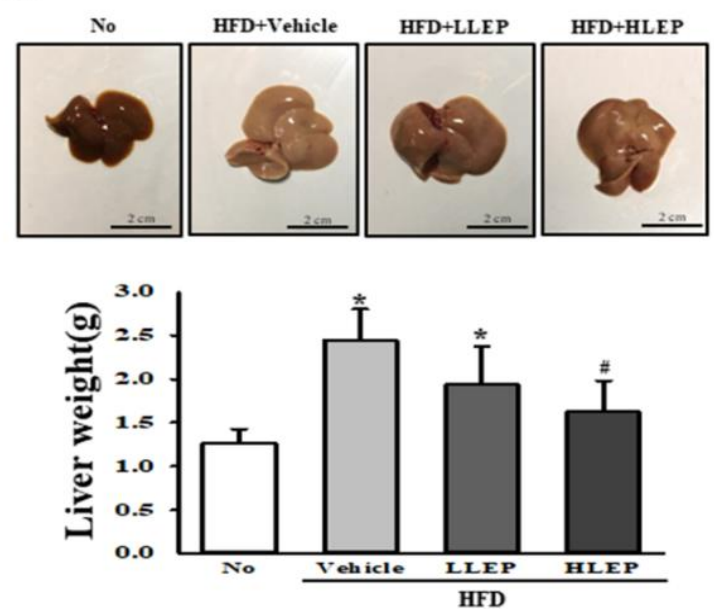

B
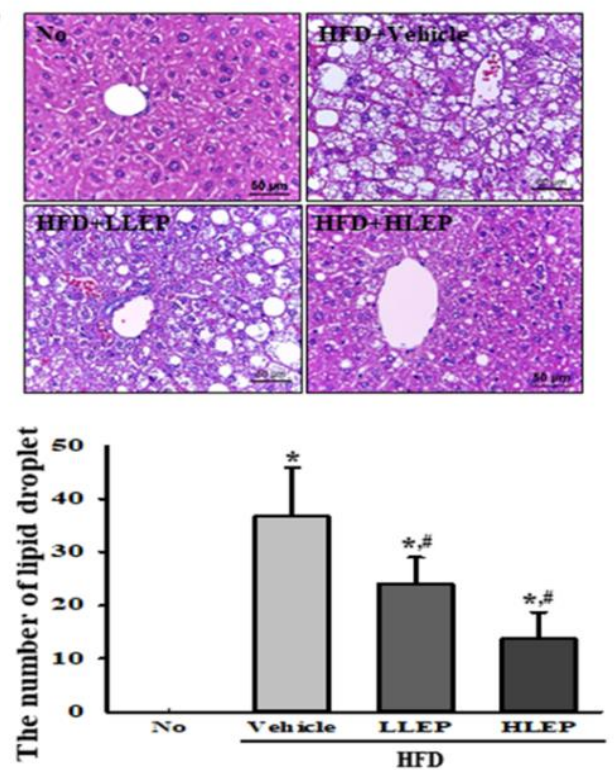

Figure 3. Measurement of liver weight and lipid droplet number in liver slide sections. (A) Livers collected from HFD-induced obese C57BL/6N mice, the subsequent to treatment with No, Vehicle, LLEP, or HLEP, were weighed using an electrical balance. Three to five mice per group were used for collecting livers, and their weight was measured in duplicate for each sample. (B) Lipid droplets were detected in H\&E stained fat sections at $200 \times$ magnification, and the total number of lipid droplets was measured using the Leica Application Suite. Five to six mice per group were used for the preparation of H\&E stained tissues, and the number of lipid droplets was counted in duplicate for each slide. Data represent the mean $\pm \mathrm{SD}$. ${ }^{*} p<0.05$ compared to the No-treated group. $\# p<0.05$ compared to the HFD + Vehicle-treated group. Abbreviations: HFD, high-fat diet; LLEP, low concentration of LEP; HLEP, high concentration of LEP.

\subsection{Effect of LEP on Adipogenesis and Lipogenesis of Liver Tissue during Anti-Hepatic Steatosis Effects}

To investigate whether anti-hepatic steatosis effects of LEP are accompanied by the inhibition of adipogenesis and lipogenesis, the mRNA levels of several key genes affecting adipogenesis, and lipogenesis were measured in the liver tissue using reverse transcription-quantitative polymerase chain reaction (RT-qPCR). Changes similar to the inhibition of hepatic steatosis were observed in the mRNA expressions of four adipogenesis and lipogenesis related genes ( $\mathrm{PPAR}_{\gamma}, \mathrm{C} / \mathrm{EBP} \alpha, \mathrm{FAS}$, and aP2) in the HFD + Vehicle- and HFD + LEP-treated groups. The mRNA levels of these genes were higher in the HFD + Vehicle-treated group than the No-treated group. However, LEP treatment induced a dose-dependent decrease of $\mathrm{PPAR}_{\gamma}, \mathrm{C} / \mathrm{EBP} \alpha, \mathrm{FAS}$, and aP2 mRNA expressions, although the decrease rates were varied (Figure $4 \mathrm{~A}-\mathrm{D}$ ). These results indicate that the anti-hepatic steatosis effect of LEP may 
be associated with the inhibition of adipogenesis and lipogenesis through the suppression of related gene expressions.
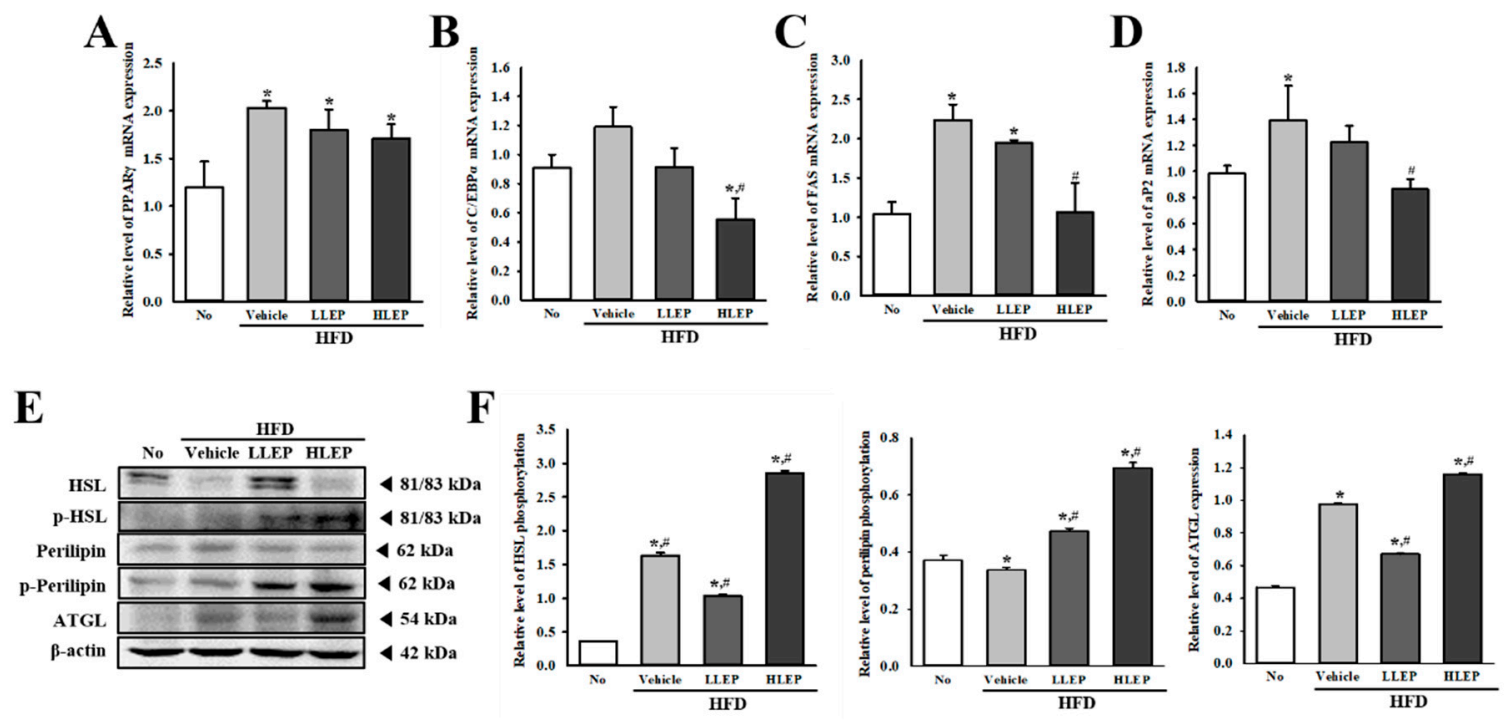

Figure 4. Expressions of lipogenesis associated genes and lipolysis associated proteins in liver tissue. HFD-induced obesity C57BL/6N mice were treated with No, Vehicle, LLEP, or HLEP for 16 weeks. RT-qPCR using specific primers was performed to analyze the expression levels of genes associated with (A,B) adipogenesis, and (C,D) lipogenesis in the liver. Three to five mice per group were used in the preparation of total RNA, and RT-qPCR were assayed in duplicate for each sample. $(\mathrm{E}, \mathrm{F})$ Western blot analysis was performed to detect the phosphorylation or expression of several lipolysis-associated proteins, including perilipin, p-perilipin, hormone-sensitive lipase (HSL), p-HSL, and adipose triglyceride lipase (ATGL). The intensity of each band was determined using an imaging densitometer, and the relative levels of the four proteins were calculated based on the intensity of actin. Three to five mice per group were used in the preparation of liver tissue homogenate, and Western blot analyses were assayed in duplicate for each sample. Data represent the mean \pm SD. * $p<0.05$ compared to the No-treated group. \# $p<0.05$ compared to the HFD + Vehicle-treated group. Abbreviations: HFD, high-fat diet; LLEP, low concentration of LEP; HLEP, high concentration of LEP; RT-qPCR, reverse transcription-quantitative polymerase chain reaction; HSL, hormone-sensitive lipase; ATGL, adipose triglyceride lipase.

\subsection{Effect of LEP on Lipolysis during Anti-Hepatic Steatosis Effects}

We further examined the molecular mechanism for the lipolytic activity of LEP to investigate whether the anti-hepatic steatosis effects of LEP induce the activation of lipolysis. To achieve this, the expression and activation of key enzymes involved in TG metabolism were analyzed in the liver tissue of HFD + LEP-treated mice. As shown in Figure 4E,F, the phosphorylation and expression level of three major enzymatic proteins (perilipin, adipose triglyceride lipase (ATGL) and hormone-sensitive lipase (HSL)) were significantly enhanced in the HFD + HLEP-treated group, as compared to the HFD + Vehicle-treated group. However, these increase patterns were not clearly observed in the HFD + LLEP-treated group. Our data indicate that the anti-hepatic steatosis effect of LEP may be associated with the activation of lipolysis.

\subsection{Inhibition Effect of LEP on HFD-Induced ER Stress}

To investigate whether anti-hepatic steatosis effects of LEP subsequently abolish ER stress, an alteration in the activation of key proteins during the ER stress response was evaluated in the liver of HFD-induced obesity mice treated with LEP. The changes in the phosphorylation and expression levels of three key proteins were very similar in all groups. The phosphorylation levels of eIF2 $\alpha$ and IRE1 $\alpha$ 
were remarkably enhanced after HFD administration, as compared to the No-treated group. However, these levels were dose-dependently inhibited in the HFD + LLEP and HFD + HLEP-treated groups (Figure 5A). A similar decrease was observed for CHOP expression, although the decrease rate differed (Figure 5A). Furthermore, the inhibitory effects of LEP in HFD-induced ER stress were evaluated for the involvement of the MAP kinase pathway. Enhanced levels of ERK, JNK, and p38 phosphorylation were variably recovered in the HFD + LLEP- and HFD + HLEP-treated groups (Figure 5B). Taken together, the above results indicate that the anti-hepatic steatosis activity of LEP successfully abolishes the HFD-induced ER stress through the regulation of the MAP kinase signaling pathway.

A

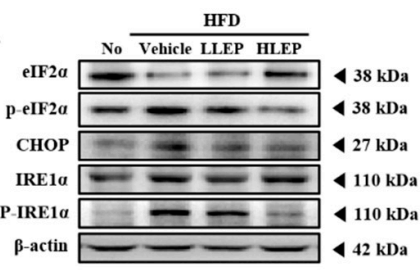

B

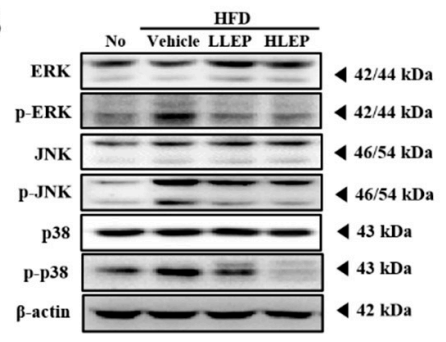


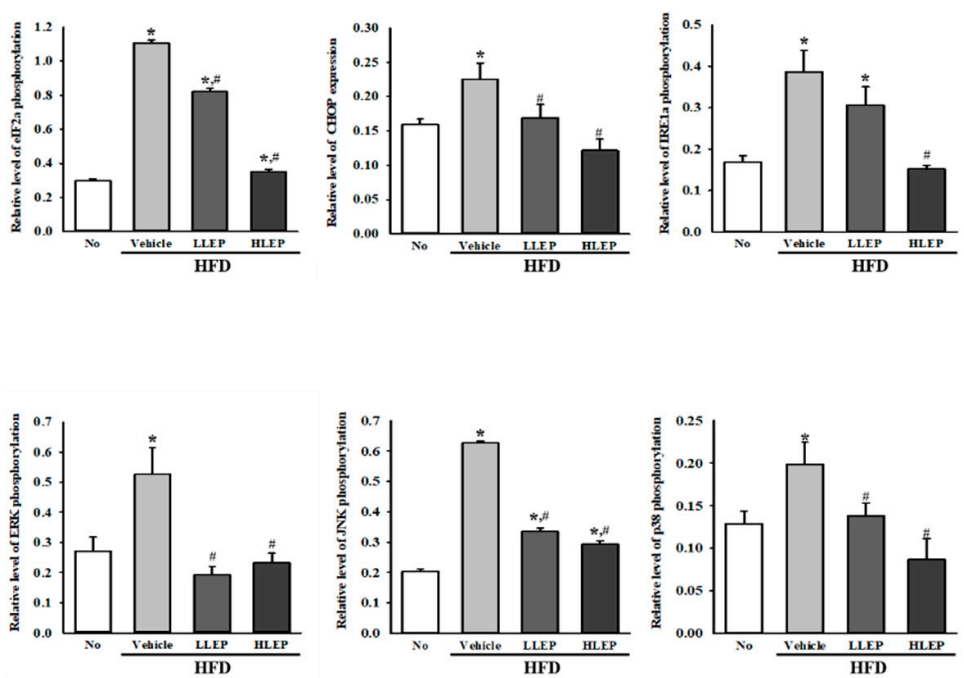
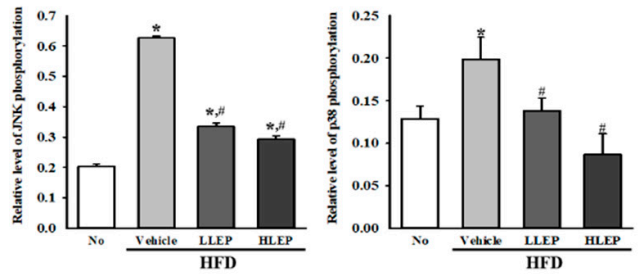

Figure 5. Expressions of key marker proteins for ER stress and MAP kinase signaling pathway in liver tissue. (A) The expression levels of ER stress markers, including eIF2 $\alpha$, p-eIF2 $\alpha$, CHOP, p-IRE1 $\alpha$ and IRE1 $\alpha$, were detected in total liver proteins using specific antibodies. (B) Using specific antibodies, the expression levels of ERK, p-ERK, JNK, p-JNK, p38, and p-p38 in the MAPK signaling pathway were detected in total liver proteins. The band intensity of proteins was determined using an imaging densitometer, and the level of each protein was calculated based on the intensity of actin protein as an endogenous control. After then, the phosphorylation level of specific protein was calculated by dividing the level of phosphorylated proteins by the level of total proteins. Three to five mice per group were used in the preparation of tissue homogenate, and Western blot analysis was assayed in duplicate for each sample. Data represent the mean \pm SD. ${ }^{*} p<0.05$ compared to the No-treated group. \# $p<0.05$ compared to the HFD + Vehicle-treated group. Abbreviations: HFD, high-fat diet; LLEP, low concentration of LEP; HLEP, high concentration of LEP; ER, Endoplasmic reticulum; MAP; mitogen-activated protein; CHOP, C/EBP homologous protein, eIF2 $\alpha$, eukaryotic translation initiation factor $2 \alpha$; IRE $1 \alpha$, inositol-requiring protein $1 \alpha$.

\subsection{Inhibition Effects of LEP on ER Stress-Mediated Autophagy during Anti-Hepatic Steatosis Effects}

The inhibitory role of LEP on autophagy in the sequential suppression of ER stress was examined by administering LEP to the HFD-induced obesity model. Alterations in the levels of markers for $\mathrm{PI} 3 \mathrm{~K} / \mathrm{AKT} / \mathrm{mTOR}$ signaling pathway and autophagy were detected in the liver tissue of HFD + LEP treated mice, with significant alterations being detected in the PI3K/AKT/mTOR signaling pathway. The phosphorylation levels of PI3K, AKT, and mTOR were higher in the HFD + Vehicle-treated group than the No-treated group. However, these levels remarkably decreased in the HFD + LEP-treated group when compared to the HFD + Vehicle-treated group (Figure 6A,B). We further examined the expression levels of Beclin1 and LC3 in the liver tissue, to investigate whether inhibition of the $\mathrm{PI} 3 \mathrm{~K} / \mathrm{AKT} / \mathrm{mTOR}$ signaling pathway after LEP treatment results in the recovery of autophagy. The levels of Beclin1 and LC3 proteins were significantly recovered in the HFD + LEP-treated group compared with the HFD + Vehicle- treated mice, although the recovery rates differed (Figure 6A,B). These results 
indicate that inhibition of ER stress induced by LEP treatment is associated with the regulation of the autophagy machinery, including the PI3K/AKT/mTOR signaling pathway and LC3 proteins.
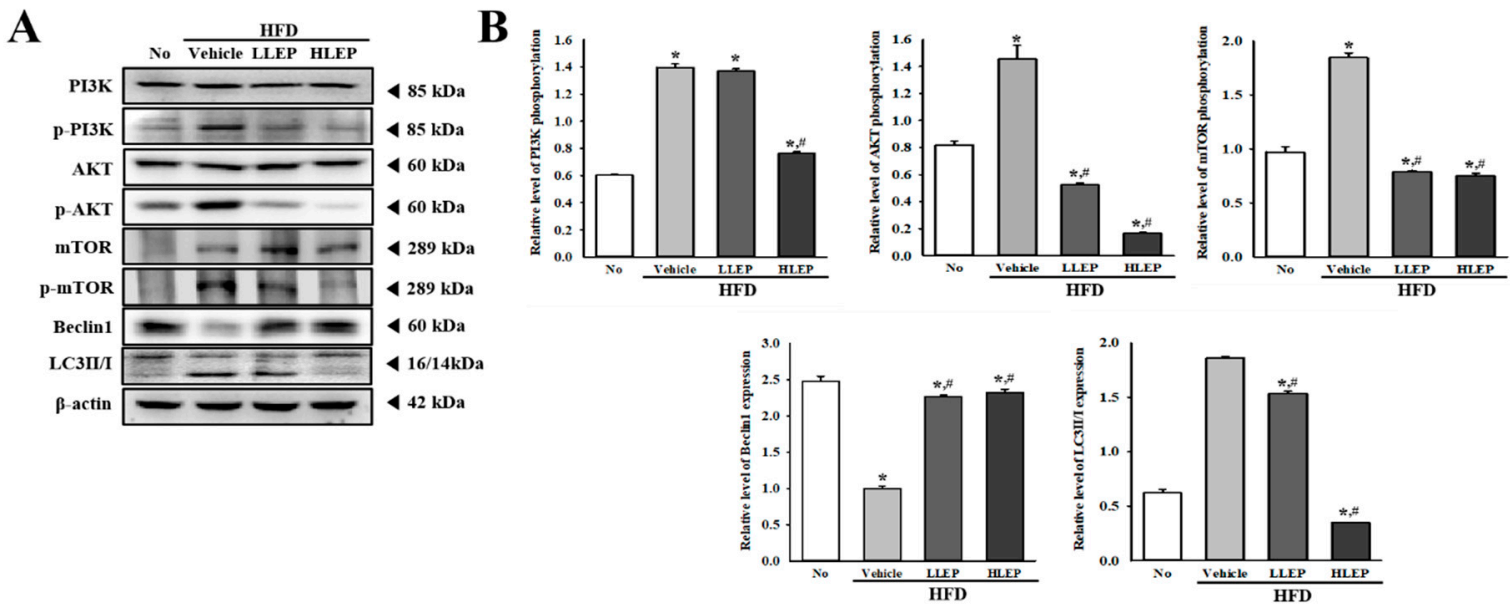

Figure 6. Expressions of key marker proteins for PI3K/AKT/mTOR pathway and autophagy in liver tissue. (A) Western blot image of marker proteins. The expression levels of PI3K, p-PI3K, AKT, p-AKT, mTOR, p-mTOR, Beclin1, and LC3II/I in total liver proteins were detected with specific antibodies. The level of $\beta$-actin is shown as the endogenous control. (B) Relative level of phosphorylation and expression of marker proteins. The band intensity of proteins was determined using an imaging densitometer, and the relative level of each protein was calculated based on the intensity of actin protein as an endogenous control. Three to five mice per group were used in the preparation of tissue homogenate, and Western blot analysis was assayed in duplicate for each sample. Data represent the mean \pm SD. * $p<0.05$ compared to the No-treated group. \# $p<0.05$ compared to the HFD + Vehicle-treated group. Abbreviations: HFD, high-fat diet; LLEP, low concentration of LEP; HLEP, high concentration of LEP; PI3k, phosphatidylinositol-3-kinase; mTOR, mammalian target of rapamycin.

\subsection{Inhibitory Effects of LEP on Autophagy-Related Gene Transcriptions during Anti-Hepatic Steatosis}

Finally, we investigated whether recovery of autophagy and PI3K/AKT/mTOR signaling pathway induces the inhibition of autophagy-related gene transcriptions. To achieve this, alterations in the mRNA expression levels of four autophagy-related genes (Autophagy-related proteins (Atg) 4b, Atg5, Atg7, and Atg12) were evaluated in the total liver RNA of HFD + LEP-treated mice. Under conditions of hepatic steatosis, transcription levels of all genes were increased in the HFD + Vehicle-treated group as compared to the No-treated group. However, these levels were significantly and dose-dependently decreased after LEP administration, although the rates were varied for each gene (Figure 7). These results indicate that the LEP-induced inhibition of autophagy may be accompanied by transcriptional regulation of the autophagy-related genes. 
A

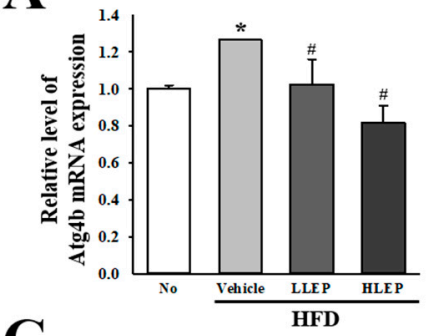

C

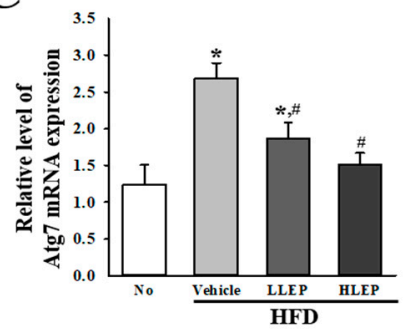

B

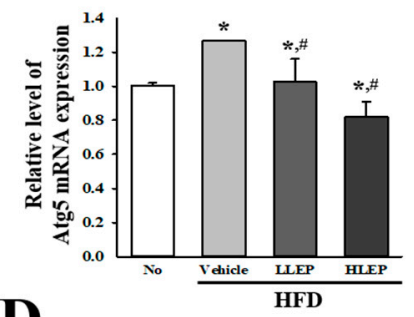

D

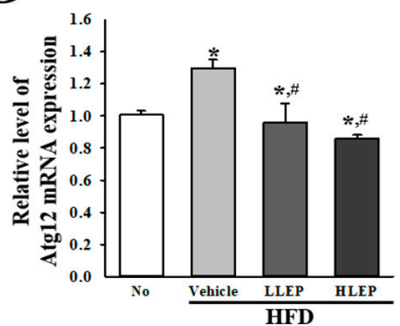

Figure 7. Transcription of autophagy-related genes in liver tissue. HFD-induced obesity C57BL/6N mice were treated with No, Vehicle, LLEP, or HLEP for 16 weeks. After purification of total RNA, the levels of (A) Atg4b, (B) Atg5, (C) Atg7, and (D) Atg12 mRNA in the total transcripts of liver tissue were measured by RT-qPCR analyses using their specific primers. The relative levels of the Atg4b, Atg5, Atg7, and Atg12 mRNA were calculated based on the intensity of $\beta$-actin as an endogenous control. Three to five mice per group were used in the preparation of the total RNAs, and RT-qPCR analysis was assayed in duplicate for each sample. Data represent the mean $\pm \mathrm{SD}$. ${ }^{*} p<0.05$ compared to the No-treated group. \# $p<0.05$ compared to the HFD + Vehicle-treated group. Abbreviations: HFD, high-fat diet; RT-qPCR, reverse transcription-quantitative polymerase chain reaction; LLEP, low concentration of LEP; HLEP, high concentration of LEP.

\section{Discussion}

The beneficial effects of perilla oil have been investigated for the regulation and treatment of obesity, although these studies were not focused on the mechanism of ER stress-mediated autophagy. Most previous studies limitedly analyzed the suppressive effects of perilla oil alleviating the body weight, organ weight, lipid profile, and fat accumulation in specific organs after treatment for $12-18$ weeks $[25,26,29]$. Also, a specific type of perilla oil extracted using the cold-pressed method was only considered to be a Western-style diet in a single [27], with no further follow-up study. The current study investigates the molecular mechanism of ER stress-mediated autophagy based on the inhibitory effect exerted by LEP for hepatic steatosis. The present results provide the first evidence of the molecular mechanism for ER stress-mediated autophagy, where the anti-hepatic steatosis effects of LEP were determined to be associated with regulation of ER stress and autophagy in the HFD-induced obesity model.

Plant essential oils are commonly isolated from various plant segments such as leaves, fruit, bark, root, wood, berries, seeds, flowers, and buds [30]. They contain numerous bioactive components, including free fatty acids, triglycerides, glycerol, phenolic compounds, and tocopherols [31]. Considering the variety of plant oils extracted, most consist of several fatty acids including $\alpha$-linolenic acid $(60.93 \%)$, oleic acid $(16.21 \%)$, linoleic acid $(14.72 \%)$, palmitic acid $(5.94 \%)$, stearic acid $(2.20 \%)$, arachidic acid $(0.2 \%)$, palmitoleic acid $(0.12 \%)$, behenic acid $(0.03 \%)$, and lignoceric acid $(0.01)$ [32] The perilla oil largely used in previous studies for anti-obesity effects contains $58 \% \alpha$-linolenic acid [25]. In the present study, a similar level of fatty acids was founded in LEP, although the amounts of $\alpha$-linolenic and linoleic acid were slightly higher (65.03\%) and lower (12.11\%), respectively. These differences could probably be attributed to the process of oil extraction and the quality of raw materials used; our study applied the cold-pressed method and used organic $P$. frutescens seed samples. 
Alterations in bodyweight gain and serum lipid profiles are important indicators to establish the efficacy of anti-obesity therapeutic drugs and related products [33]. These alterations have also been observed in the HFD-induced obesity model treated with various essential oils. The treatment of garlic essential oil, citronella oil, ginger essential oil, black currant seed oil, and sweet orange essential oil are reported to induce a decrease in the bodyweight gain, as well as a decrease in the TG and TC levels in the HFD-induced obesity model [34-38]. Similar results were observed in the lipid profile of animals treated with perilla oil. Serum levels of TC, TG, and LDL-C were significantly decreased in the HFD-induced model after treatment with perilla oil. However, all mice treated with perilla oil and related diet remained their weight as a constant level [25-28]. In our study, although no significant change was detected in the bodyweight of HFD + LEP-treated mice, the TC, TG and LDL-C levels were decreased after LEP administration. Our results are very similar to previously reported results that evaluated the anti-obesity effects of perilla oil in the HFD-treated model. However, further research using essential oils of other plants and perilla oil is required to determine the difference in efficacy on weight loss.

Our study results indicate that LEP treatment for 16 weeks ameliorates the HFD-induced hepatic steatosis in C57BL/6N mice. The number of lipid droplets strongly decreased in the liver of HFD + LLEPand HFD + HLEP-treated groups (Figure 3). These results are consistent with previous studies that report the reduction of HFD-hepatic steatosis after treatment with perilla oil. Histopathological analyses of liver tissue have revealed that the perilla oil-rich diet and Western-style diet containing $5.5 \%$ perilla oil reduce hepatic steatosis in the HFD-treated Sprague Dawley (SD) rats [26,27]. Moreover, $200 \mathrm{mg} / \mathrm{kg}$ or $1000 \mathrm{mg} / \mathrm{kg} /$ day of perilla oil decreased the hepatic lipid accumulation and improved the balance of lipogenic and lipolytic protein [28]. However, it is difficult to directly compare the degree of anti-hepatic steatosis effects between studies since the analysis methods differed in each study.

ER stress is induced when unfolded and misfolded proteins excessively accumulate in the ER lumen, or when calcium levels increase in the ER exhaust [39]. Studies in several animal models have reported that ER stress is tightly related to hepatic steatosis. Direct enhancement of ER stress induced with chemical agents and genetic mutations of ER stress molecules (including PERK/eIF2 $\alpha$, IRE1/ X-box binding protein 1 (XBP1) and ATF6) stimulate hepatic steatosis via controlling lipid synthesis and the inflammatory response $[7,40,41]$. Conversely, the pathogenesis of hepatic steatosis and obesity induces the ER stress response. Especially, HFD treatment induces the development of hepatic steatosis, type 2 diabetes, and insulin resistance, as well as increases the expressions of ER stress markers in liver tissue [42-44]. Therefore, the relationship between ER stress and hepatic steatosis is bilateral, since steatosis promotes ER stress, and the ER stress response leads to steatosis [45]. However, previous studies have not investigated whether the anti-obesity effect of plant essential oils is associated with ER stress. Therefore, in the current study, alteration of ER stress markers was analyzed in the liver tissue of HFD + LEP-treated mice, to investigate the mechanism and role of LEP during the anti-hepatic steatosis. Our results provide the first evidence that the anti-hepatic steatosis effects of LEP may tightly be linked to the regulation of eIF2 $\alpha$, IRE1 $\alpha$, and CHOP associated with the ER stress responses.

Finally, ER stress-mediated autophagy is tightly controlled to maintain homeostasis in the liver tissue of obese mice, although there is a lack of scientific evidence. In the liver of lean type mice, impairment of autophagy increases the ER stress, whereas rescuing induces the downregulation of ER stress markers such as LC3, Beclin1, Atg5, and Atg7 in the ob/ob and HFD-induced model [42]. Also, the levels of LC3, LC3-II, and p62 in autophagosome were reported to be enhanced in the non-alcoholic steatohepatitis (NASH) murine model, but patients with NASH show an increase of only p62 level [42,46-48]. A significant increase of several autophagy markers has been reported in the liver tissue of various animal models, including ob/ob mice [49], the HFD-treated C57BL/6J mice [50], and HFD-treated Wistar rats [51]. Furthermore, these enhanced marker levels were significantly reduced in the hepatic steatosis animal models after treatment with natural products, including grape seed proanthocyanidins [52], extracts of Abelmoschus manihot [28], Jiang Zhi [53], and epigallocatechin-3-gallate [54]; however, there was no study applying vegetable oil. Based on the above-associated studies, the present study especially 
focused on the applicability of this target in anti-hepatic steatosis activity of LEP. Our results provide the first evidence that LEP with anti-hepatic steatosis effects inhibits the ER stress-mediated autophagy in HFD-induced obesity models through the regulation of the PI3K/AKT/mTOR pathway. These results are in full agreement with previous results derived from the HFD-induced model after the administration of anti-autophagy products, although the treated products and analysis markers are different.

\section{Materials and Methods}

\subsection{Extraction and Composition Analyses of LEP}

Seed samples of Perilla frutescens were collected in October 2017 from plantations in Myrang City (Korea), and were characterized by Dr. Chung Yeoul Lee, Research Director at Gangrim Organics Co. (Miryang, Korea). Voucher specimens (WPC-18-001) were deposited in the Functional Materials Bank at the Pusan National University-Wellbeing Regional Innovation System (RIS) Center. Briefly, seeds of $P$. frutescens were washed with tap water and subsequently dried in a hot-air drying machine (JSR, Seoul, Korea) for $24 \mathrm{~h}$ at $60^{\circ} \mathrm{C}$. LEP was produced using a cold-press machine (Pungjin Food Machin Co., Mokpo, Korea) at $60 \mathrm{MPa}$, followed by filtration through a 6-8 $\mu \mathrm{m}$ membrane filter. The yield of LEP was determined to be $25-30 \mathrm{~mL} / 100 \mathrm{~g}$ of seed samples. The composition and calorie contents of LEP were analyzed on an FID-equipped Gas Chromatograph (Agilent Technologies, Santa Clara, CA, USA) at the Traditional Microorganism Resources Center of Keimyung University. The calorie of LEP was determined to be $829 \mathrm{Kcal} / 100 \mathrm{~mL}$.

\subsection{Design of Animal Experiment}

Eight-week-old C57BL/6N male mice were purchased from Samtako BioKorea Inc. (Osan, Korea), and provided ad libitum access to water and a standard irradiated chow diet (Samtako Bio-Korea Inc.). During the experiment, mice were maintained in specific pathogen-free (SPF) conditions under a strict light cycle (lights on at $08: 00 \mathrm{~h}$ and off at $20: 00 \mathrm{~h}$ ) at $23 \pm 2{ }^{\circ} \mathrm{C}$ and $50 \pm 10 \%$ relative humidity. All C57BL/6N mice were handled at the Pusan National University-Laboratory Animal Resources Center, accredited by the Korea Food and Drug Administration (KFDA) (Accredited Unit Number-000231), and AAALAC International (Accredited Unit Number; 001525).

The Institutional Animal Care and Use Committee-Pusan National University (IACUC-PNU) approved the protocol for the animal experiment (PNU-2018-2011). All mice were acclimatized on a normal diet (D12450K; Research Diets, New Brunswick, NJ, USA) for 1 week. The C57BL/6N mice were then divided into four experimental groups (seven mice/group): (1) control group fed a normal diet (No-treated group), (2) group fed HFD plus Vehicle (Corn oil $10 \mathrm{~mL} / \mathrm{kg}$ ) (HFD + Vehicle-treated group), (3) group fed HFD plus 50\% diluted LEP in corn oil $10 \mathrm{~mL} / \mathrm{kg}$ (HFD + LLEP-treated group), and (4) group fed HFD plus original LEP of $10 \mathrm{~mL} / \mathrm{kg}$ (HFD + HLEP-treated group). Mice of all HFD treatment groups consumed HFD containing 60\% kcal fat purchased from Research Diets (\#D12492, Research Diets, New Brunswick, USA) for 16 weeks. After $24 \mathrm{~h}$ of the final LEP treatment, all mice were euthanized using $\mathrm{CO}_{2}$ gas. The tissue samples and blood serum were subsequently acquired and stored in Eppendorf tubes at $-70{ }^{\circ} \mathrm{C}$, until assay.

\subsection{Measurement of Body, Liver, and Abdominal Fat Weight}

Throughout the experimental period, the bodyweight of mice treated with Vehicle or LEP was measured daily at 10:00 a.m. using an electronic balance (\#AD-2.5 Mettler Toledo, Greifensee, Switzerland), according to the KFDA guidelines. In addition, the weights of liver and abdominal fat collected from the sacrificed C57BL/6N mice were determined using the same method employed to measure the body weight. 


\subsection{Serum Biochemical Analysis}

After 16 weeks of feeding HFD diets and administrating LEP, whole blood was collected from the abdominal veins of all C57BL/6N mice after $18 \mathrm{~h}$ fasting. The blood samples were incubated for $30 \mathrm{~min}$ at room temperature in serum separating tubes (BD container, Franklin Lakes, NJ, USA), and serum was obtained by centrifugation at $1500 \times g$ for $15 \mathrm{~min}$. Serum GLU, TC, TG, HDL-C, and LDL-C concentrations were analyzed by the automatic chemical analyzer (BS-120 Chemistry Analyzer, Mindray, China). All assays were conducted in duplicate using fresh serum.

\subsection{Histopathological Analysis}

Liver and fat tissues collected from mice of all subset groups were fixed overnight in $10 \%$ neutral buffered formaldehyde ( $\mathrm{pH}$ 6.8). The dehydrated liver tissue was then embedded in paraffin wax. Next, a series of liver and fat sections $(4 \mu \mathrm{m})$ were cut from the paraffin-embedded tissues using a Leica microtome (\#DM500, Leica Microsystems, Bannockburn, IL, USA). These sections were collected on glass slides, deparaffinized with xylene (\#8587-4410, DAEJUNG, Gyeonggi-do, Korea), rehydrated with graded ethanol (decreasing concentrations of 100-70\%), and finally washed with distilled water. The liver and fat section slides were stained with hematoxylin (\#MHS16, Sigma-Aldrich, St. Louis, MO, USA) and eosin (\#HT110332, Sigma-Aldrich), washed with $\mathrm{dH}_{2} \mathrm{O}$, and the number of lipid droplets was counted under the Leica Application Suite (Leica Microsystems, Heerbrugg, Switzerland). Also, the area occupied by adipocytes in the fat section was measured using the Image J program 1.52a (NIH, Bethesda, ML, USA).

\subsection{RT-qPCR Analysis}

Frozen liver tissue was chopped with scissors and homogenized in RNA Bee solution (\#CS-105B, Tet-Test, Friendswood, TX, USA). Total RNA molecules were isolated by centrifugation at 15,000 rpm for $15 \mathrm{~min}$, after which the concentration was measured by Nano Drop Spectrophotometers (Allsheng, Hangzhou, China). To examine the expression of each genes, total RNA (5 $\mu \mathrm{g})$ from liver tissue was annealed with $500 \mathrm{ng}$ of oligo-dT primer (\#18418-012, Thermo Fisher Scientific, Wilmington, MA, USA) at $70{ }^{\circ} \mathrm{C}$ for $10 \mathrm{~min}$. The complementary DNA (cDNA) was synthesized by Invitrogen Superscript II reverse transcriptase (\#4376600, Thermo Fisher Scientific). qPCR was performed with the cDNA template $(2 \mu \mathrm{L})$ and $2 \times$ Power SYBR Green $(6 \mu \mathrm{L}$; Toyobo Life Science, Osaka, Japan) containing specific primers. The primer sequences for target gene expression identification used were presented in Table 2 . qPCR was performed for 40 cycles using the following sequence: denaturation at $95^{\circ} \mathrm{C}$ for $15 \mathrm{sec}$, followed by annealing and extension at $70{ }^{\circ} \mathrm{C}$ for $60 \mathrm{sec}$. Fluorescence intensity was measured at the end of the extension phase of each cycle. Threshold value for the fluorescence intensities of all samples was set manually. The reaction cycle at which the PCR products exceeded this fluorescence intensity threshold during the exponential phase of PCR amplification was considered, as the threshold cycle $(\mathrm{Ct})$. Expression of the target gene was quantified relative to that of the housekeeping gene $\beta$-actin, based on a comparison of the Cts at constant fluorescence intensity, as per the Livak and Schmittgen's method [55]. 
Table 2. Primer sequences for RT-PCR analyses.

\begin{tabular}{|c|c|c|}
\hline Primer Name & Sequence (from $5^{\prime}$ to $3^{\prime}$ ) & Product Size (bp) \\
\hline \multicolumn{3}{|l|}{ PPAR- $\gamma$} \\
\hline Forward & GAG TTC ATG CTT GTG AAG GAT GCA AGG & \multirow{2}{*}{528} \\
\hline Reverse & CAT ACT CTG TGA TCT CTT GCA CG & \\
\hline \multicolumn{3}{|l|}{$\mathrm{C} / \mathrm{EBP} \alpha$} \\
\hline Forward & GTG GAC AAG AAC AGC AAC GAG TAC & \multirow{2}{*}{363} \\
\hline Reverse & GGA ATC TCC TAG TCC TGG CTT GC & \\
\hline \multicolumn{3}{|l|}{ FAS } \\
\hline Forward & GAT CCT GGA ACG AGA ACA CGA TCT GG & \multirow{2}{*}{285} \\
\hline Reverse & AGA CTG TGG AAC ACG GTG GTG GAA CC & \\
\hline \multicolumn{3}{|l|}{ aP2 } \\
\hline Forward & GAA CCT GGA AGC TTG TCT CCA GTG & \multirow{2}{*}{233} \\
\hline Reverse & GAT GCT CTT CAC CTT CCT GTC GTC TGC & \\
\hline \multicolumn{3}{|l|}{$\operatorname{Atg} 4 b$} \\
\hline Forward & CTA TGT GGA GAC GCT GAA GCA CTG TTT C & \multirow{2}{*}{423} \\
\hline Reverse & СTC TCC AGT CTC TCT ACA TCA GAA GAG & \\
\hline \multicolumn{3}{|l|}{$\operatorname{Atg} 5$} \\
\hline Forward & CCA AGA GTC AGC TAT TTG ACG & \multirow{2}{*}{178} \\
\hline Reverse & TCC AAG GAA GAG CTG AAC TTG & \\
\hline \multicolumn{3}{|l|}{$\operatorname{Atg} 7$} \\
\hline Forward & CCT TGC TCA AAC ACT ACA GTG & \multirow{2}{*}{216} \\
\hline Reverse & TGC TAT GTG TCA CGT CTC TAG & \\
\hline \multicolumn{3}{|l|}{$\operatorname{Atg} 12$} \\
\hline Forward & CCA TCC AAG GAC TCA TTG AC & \multirow{2}{*}{166} \\
\hline Reverse & TTG CAG TAA TGC AGG ACC AG & \\
\hline \multicolumn{3}{|l|}{$\beta$-actin } \\
\hline Forward & TGG AAT CCT GTG GCA TCC ATG AAA C & \multirow{2}{*}{349} \\
\hline Reverse & TAA AAC GCA GCT CAG TAA CAG TCC G & \\
\hline
\end{tabular}

\subsection{Western Blot Analysis}

Liver tissue $(50 \mathrm{mg})$ collected from each mice of subset groups was homogenized using the PRO-PREPTM Solution (\#170841, iNtRON Biotechnology, Sungnam, Korea), and total protein extracts were collected by centrifugation at 13,000 rpm for $5 \mathrm{~min}$. Protein concentrations were determined with the Pierce ${ }^{\mathrm{TM}}$ Bicinchonic Acid (BCA) Protein Assay Kit (Thermo Fisher Scientific). The prepared proteins $(30 \mu \mathrm{g})$ were subsequently subjected to $10 \%$ sodium dodecyl sulfate-polyacrylamide gel electrophoresis (SDS-PAGE) for $2 \mathrm{~h}$ at $100 \mathrm{~V}$, and transferred to a nitrocellulose membrane (GE Healthcare, Little Chalfont, UK) for $2 \mathrm{~h}$ at $40 \mathrm{~V}$ in transfer buffer ( $25 \mathrm{mM}$ Trizma-base, $192 \mathrm{mM}$ glycine, and 20\% methanol). Membranes were then exposed to appropriate dilutions of primary antibodies and allowed to hybridize overnight at $4{ }^{\circ} \mathrm{C}$; following antibodies were used: anti-HSL (\#4107S, Cell Signaling Technology, Danvers, MA, USA), anti-p-HSL (\#4139S, Cell Signaling Technology), anti-perilipin (\#9349S, Cell Signaling Technology), anti-p-perilipin (\#9621S, Cell Signaling Technology), anti-ATGL (\#2138S, Cell Signaling Technology), anti-Beclin1 (\#3738s, Cell Signaling Technology), anti-LC3-I/II (\#3868s, Cell Signaling Technology), anti-PI3K (\#4292s, Cell Signaling Technology), anti-p-PI3K (\#4228s, Cell Signaling Technology), anti-AKT (\#9272s, Cell Signaling Technology), anti-p-AKT (\#4058s, Cell Signaling Technology), anti-mTOR (\#2972s, Cell Signaling Technology), anti-p-mTOR (\#2971s, Cell Signaling Technology), anti-JNK (\#9252s, Cell signaling Technology), anti-p-JNK (\#9251s, Cell signaling Technology), anti-ERK1/2 (\#9102s, Cell signaling Technology), anti-p-ERK1/2 (\#sc-7383, 
Santa Cruz Biotechnology, Dallas, TX, USA), anti-p38 (\#9212s, Cell Signaling Technology), anti-p-p38 (\#9211s, Cell Signaling Technology), anti-eIF2 $\alpha$ (\#9722S, Cell Signaling Technology), anti-p-eIF2 $\alpha$ (\#9721S, Cell Signaling Technology), anti-CHOP (\#2895S, Cell Signaling Technology), anti-IRE1 $\alpha$ (\#NB100-2324, Novus Biologicals, Littleton, CO, USA), anti-p-IRE1 $\alpha$ (\#NB100-2323, Novus Biologicals), and anti- $\beta$-actin (\#4967S, Cell Signaling Technology). The membranes were washed three times in a $10 \mathrm{mM}$ Trizma-base $(150 \mathrm{mM} \mathrm{NaCl}$ and $0.05 \%$ Tween-20) solution for $10 \mathrm{~min}$ upon removal primary antibodies solution and subsequently incubated with horseradish peroxidase-conjugated secondary antibody for $1 \mathrm{~h}$ at room temperature, after which they were washed again as described above, and developed using an enhanced chemiluminescence reagent plus kit (\#DG-WF100, Dogen, Seoul, Korea). Finally, the results were quantified using the Image Analyzer System (Fluorchem FC2, Alpha Innotech, CA, USA) and expressed as the fold increase over the control values.

\subsection{Statistical Significance Analysis}

One-way ANOVA (SPSS for Windows, Release 10.10, Standard Version, Chicago, IL, USA) was used to determine the variance and identify significant differences between the No-treated group and the HFD fed groups, as well as between the Vehicle and LEP-treated groups. All values are presented as the means \pm standard deviation (SD). A $p$-value $<0.05$ is considered significant.

\section{Conclusions}

Taken together, the results of the current study demonstrate that LEP exerts anti-hepatic steatosis activity by successfully suppressing adipogenesis and lipogenesis, as well as activating lipolysis in the liver tissue of HFD-induced obese mice. In addition, the anti-hepatic steatosis effects of LEP are accompanied by suppression of ER stress-mediated autophagy, including the MAPK and $\mathrm{PI} 3 \mathrm{~K} / \mathrm{AKT} / \mathrm{mTOR}$ signaling pathways. The regulatory effects of LEP on the ER stress response and autophagy during the suppression of hepatic steatosis indicates the potential of LEP as an anti-obesity drug that reduces fat accumulation.

Author Contributions: Conceptualization, D.Y.H.; Methodology, D.Y.H., S.J.B.; Validation, S.J.B., J.E.K.; Formal analysis, S.J.B., H.S.L.; Investigation, S.J.B., H.J.C., Y.J.C., S.J.L. and J.E.G.; Data curation, S.J.B., J.E.K.; Writing — original draft preparation, D.Y.H.; Writing—review and editing, S.S., S.Y.Y., B.-S.A., D.S.K. and C.Y.L.; Visualization, D.Y.H. and S.J.B.; Supervision, D.Y.H.; Project administration, D.Y.H.; Funding acquisition, D.Y.H. All authors have read and agreed to the published version of the manuscript.

Funding: This study was supported by grants to Dae Youn Hwang from the Gangrim Organics.

Acknowledgments: We thank Jin Hyang Hwang, the animal technician, for directing the animal care at the Laboratory Animal Resources Center in Pusan National University.

Conflicts of Interest: The authors declare no conflict of interest.

\section{References}

1. Browning, J.D.; Horton, J.D. Molecular mediators of hepatic steatosis and liver injury. J. Clin. Investig. 2004, 114, 147-152. [CrossRef] [PubMed]

2. Cohen, J.C.; Horton, J.D. Hobbs, H.H. Human fatty liver disease: Old questions and new insights. Science 2011, 332, 1519-1523. [CrossRef] [PubMed]

3. Falck-Ytter, Y.; Younossi, Z.M.; Marchesini, G.; McCullough, A.J. Clinical features and natural history of nonalcoholic steatosis syndromes. Semin. Liver Dis. 2001, 21, 17-26. [CrossRef] [PubMed]

4. Treeprasertsuk, S.; Leverage, S.; Adams, L.A.; Lindor, K.D.; St Sauver, J.; Angulo, P. The Framingham risk score and heart disease in nonalcoholic fatty liver disease. Liver Int. 2012, 32, 945-950. [CrossRef] [PubMed]

5. Ozcan, U.; Yilmaz, E.; Ozcan, L.; Furuhashi, M.; Vaillancourt, E.; Smith, R.O.; Görgün, C.Z.; Hotamisligil, G.S. Chemical chaperones reduce ER stress and restore glucose homeostasis in a mouse model of type 2 diabetes. Science 2006, 313, 1137-1140. [CrossRef] 
6. Ozcan, U.; Cao, Q.; Yilmaz, E.; Lee, A.H.; Iwakoshi, N.N.; Ozdelen, E.; Tuncman, G.; Görgün, C.; Glimcher, L.H.; Hotamisligil, G.S. Endoplasmic reticulum stress links obesity, insulin action, and type 2 diabetes. Science 2004, 306, 457-461. [CrossRef]

7. Zhang, K.; Wang, S.; Malhotra, J.; Hassler, J.R.; Back, S.H.; Wang, G.; Chang, L.; Xu, W.; Miao, H.; Leonardi, R.; et al. The unfolded protein response transducer IRE1alpha prevents ER stress-induced hepatic steatosis. EMBO J. 2011, 30, 1357-1375. [CrossRef]

8. Lee, J.S.; Mendez, R.; Heng, H.H.; Yang, Z.Q.; Zhang, K. Pharmacological ER stress promotes hepatic lipogenesis and lipid droplet formation. Am. J. Transl. Res. 2012, 4, 102-113.

9. Lee, J.S.; Zheng, Z.; Mendez, R.; Ha, S.W.; Xie, Y.; Zhang, K. Pharmacologic ER stress induces non-alcoholic steatohepatitis in an animal model. Toxicol. Lett. 2012, 211, 29-38. [CrossRef]

10. Kawasaki, N.; Asada, R.; Saito, A.; Kanemoto, S.; Imaizumi, K. Obesity-induced endoplasmic reticulum stress causes chronic inflammation in adipose tissue. Sci. Rep. 2012, 2. [CrossRef]

11. Guo, B.; Li, Z. Endoplasmic reticulum stress in hepatic steatosis and inflammatory bowel diseases. Front. Genet. 2014, 5. [CrossRef] [PubMed]

12. Czaja, M.J. Function of autophagy in nonalcoholic fatty liver disease. Dig. Dis. Sci. 2016, 61, 1304-1313. [CrossRef] [PubMed]

13. Mao, Y.; Yu, F.; Wang, J.; Guo, C.; Fan, X. Autophagy: A new target for nonalcoholic fatty liver disease therapy. Hepat. Med. 2016, 8, 27-37. [CrossRef]

14. Pan, Q.R.; Ren, Y.L.; Liu, W.X.; Hu, Y.J.; Zheng, J.S.; Xu, Y.; Wang, G. Resveratrol prevents hepatic steatosis and endoplasmic reticulum stress and regulates the expression of genes involved in lipid metabolism, insulin resistance, and inflammation in rats. Nutr. Res. 2015, 35, 576-584. [CrossRef] [PubMed]

15. Zhao, M.; Zang, B.; Cheng, M.; Ma, Y.; Yang, Y.; Yang, N. Differential responses of hepatic endoplasmic reticulum stress and inflammation in diet-induced obese rats with high-fat diet rich in lard oil or soybean oil. PLoS ONE 2013, 8, e78620. [CrossRef]

16. Peng, Y.; Ye, J.; Kong, J. Determination of phenolic compounds in Perilla frutescens L. by capillary electrophoresis with electrochemical detection. J. Agric. Food Chem. 2005, 53, 8141-8147. [CrossRef]

17. Chatgilialoglu, C.; Ferreri, C.; Melchiorre, M.; Sansone, A.; Torreggiani, A. Lipid geometrical isomerism: From chemistry to biology and diagnostics. Chem. Rev. 2014, 114, 255-284. [CrossRef]

18. Akoh, C.C.; Min, D.B. Food Lipids: Chemistry, Nutrition, and Biotechnology, 3rd ed.; CRC Press: Boca Raton, FL, USA, 2008; pp. 39-62.

19. Chow, C.K. Fatty Acids in Foods and Their Health Implication, 3rd ed.; CRC Press: Boca Raton, FL, USA, 2008; pp. 227-262.

20. Calder, P.C. n-3 Polyunsaturated fatty acids, inflammation, and inflammatory diseases. Am. J. Clin. Nutr. 2006, 83, 1505-1519. [CrossRef]

21. Dhyani, A.; Chopra, R.; Garg, M. A review on nutritional value, functional properties and pharmacological application of perilla (Perilla Frutescens L.). Biomed. Pharmacol. J. 2019, 12, 649-660. [CrossRef]

22. Bachheti, R.K.; Joshi, A.; Ahmed, T.A. Phytopharmacological overview on Perilla frutescens. Int. J. Pharm. Sci. Rev. Res. 2014, 26, 55-61.

23. Seong, J.; Song, Y.O. Perilla oil rich in alpha-linolenic acid inhibits neuronal apoptosis and the expression of inflammation-mediator protein in apoE KO mice. Biocatal. Agric. Biotechnol. 2012, 1, 167-173. [CrossRef]

24. Zhao, G.; Qin, G.W.; Wang, J.; Chu, W.J.; Guo, L.H. Functional activation of monoamine transporters by luteolin and apigenin isolated from the fruit of Perilla frutescens (L.) Britt. Neurochem. Int. 2010, 56, 168-176. [CrossRef] [PubMed]

25. Ikemoto, S.; Takahashi, M.; Tsunoda, N.; Maruyama, K.; Itakura, H.; Ezaki, O. High-fat diet-induced hyperglycemia and obesity in mice: Differential effects of dietary oils. Metabolism 1996, 45, 1539-1546. [CrossRef]

26. Tian, Y.; Wang, H.; Yuan, F.; Li, N.; Huang, Q.; He, L.; Wang, L.; Liu, Z. Perilla oil has similar protective effects of fish oil on high-fat diet-induced nonalcoholic fatty liver disease and gut dysbiosis. Biomed. Res. Int. 2016, 2016. [CrossRef] [PubMed]

27. Chen, T.; Yuan, F.; Wang, H.; Tian, Y.; He, L.; Shao, Y.; Li, N.; Liu, Z. Perilla oil supplementation ameliorates high-fat/high-cholesterol diet induced nonalcoholic fatty liver disease in rats via enhanced fecal cholesterol and bile acid excretion. Biomed. Res. Int. 2016, 2016. [CrossRef] [PubMed] 
28. Kim, H.; Dusabimana, T.; Kim, S.R.; Je, J.; Jeong, K.; Kang, M.C.; Cho, K.M.; Kim, H.J.; Park, S.W. Supplementation of abelmoschus manihot ameliorates diabetic nephropathy and hepatic steatosis by activating autophagy in mice. Nutrients 2018, 10, 1703. [CrossRef]

29. Kim, S.R.; Je, J.; Jeong, K.; Kim, S.J.; Lee, K.Y.; Choi, S.G.; Kim, H.; Park, S.W. Perilla oil decreases aortic and hepatic lipid accumulation by modulating lipogenesis and lipolysis in high-fat diet-fed mice. J. Med. Food 2019, 22, 14-21. [CrossRef]

30. Sankarikutty, B.; Narayanan, C.S. ESSENTIAL OILS|Isolation and Production. In Encyclopedia of Food Sciences and Nutrition, 2nd ed.; Benjamin, C., Ed.; Academic Press: Cambridge, MA, USA, 2003; pp. 2185-2189.

31. Orsavova, J.; Misurcova, L.; Ambrozova, J.V.; Vicha, R.; Mlcek, J. Fatty acids composition of vegetable oils and its contribution to dietary energy intake and dependence of cardiovascular mortality on dietary intake of fatty acids. Int. J. Mol. Sci. 2015, 16, 12871-12890. [CrossRef]

32. Ciftci, O.N.; Przybylski, R.; Rudzinska, M. Lipid components of flax, perilla, and chia seeds. Eur. J. Lipid Sci. Technol. 2012, 114, 794-800. [CrossRef]

33. Hutton, B.; Fergusson, D. Changes in body weight and serum lipid profile in obese patients treated with orlistat in addition to a hypocaloric diet: A systematic review of randomized clinical trials. Am. J. Clin. Nutr. 2004, 80, 1461-1468. [CrossRef]

34. Lai, Y.S.; Chen, W.C.; Ho, C.T.; Lu, K.H.; Lin, S.H.; Tseng, H.C.; Lin, S.Y.; Sheen, L.Y. Garlic essential oil protects against obesity-triggered nonalcoholic fatty liver disease through modulation of lipid metabolism and oxidative stress. J. Agric. Food Chem. 2014, 62, 5897-5906. [CrossRef] [PubMed]

35. Batubara, I.; Suparto, I.H.; Sa'diah, S.; Matsuoka, R.; Mitsunaga, T. Effects of inhaled citronella oil and related compounds on rat body weight and brown adipose tissue sympathetic nerve. Nutrients 2015, 7, 1859-1870. [CrossRef] [PubMed]

36. Jurgoński, A.; Fotschki, B.; Juśkiewicz, J. Disparate metabolic effects of blackcurrant seed oil in rats fed a basal and obesogenic diet. Eur. J. Nutr. 2015, 54, 991-999. [CrossRef] [PubMed]

37. Lai, Y.S.; Lee, W.C.; Lin, Y.E.; Ho, C.T.; Lu, K.H.; Lin, S.H.; Panyod, S.; Chu, Y.L.; Sheen, L.Y. Ginger essential oil ameliorates hepatic injury and lipid accumulation in high-fatdiet-induced nonalcoholic fatty liver disease. J. Agric. Food Chem. 2016, 64, 2062-2071. [CrossRef] [PubMed]

38. Li, D.; Wu, H.; Dou, H. Weight loss effect of sweet orange essential oil microcapsules on obese SD rats induced by high-fat diet. Biosci. Biotechnol. Biochem. 2019, 83, 923-932. [CrossRef] [PubMed]

39. Malhi, H.; Kaufman, R.J. Endoplasmic reticulum stress in liver disease. J. Hepatol. 2011, 54, 795-809. [CrossRef]

40. Pagliassotti, M.J. Endoplasmic reticulum stress in nonalcoholic fatty liver disease. Annu. Rev. Nutr. 2012, 32, 17-33. [CrossRef]

41. Li, J.; Huang, J.; Li, J.S.; Chen, H.; Huang, K.; Zheng, L. Accumulation of endoplasmic reticulum stress and lipogenesis in the liver through generational effects of high-fat diets. J. Hepatol. 2012, 56, 900-907. [CrossRef]

42. Yang, L.; Li, P.; Fu, S.; Calay, E.S.; Hotamisligil, G.S. Defective hepatic autophagy in obesity promotes ER stress and causes insulin resistance. Cell. Metab. 2010, 11, 467-478. [CrossRef]

43. Zhou, L.; Liu, F. Autophagy: Roles in obesity-induced ER stress and adiponectin downregulation in adipocytes. Autophagy 2010, 6, 1196-1197. [CrossRef]

44. Birkenfeld, A.L.; Lee, H.Y.; Majumdar, S.; Jurczak, M.J.; Camporez, J.P.; Jornayvaz, F.R.; Frederick, D.W.; Guigni, B.; Kahn, M.; Zhang, D.; et al. Influence of the hepatic eukaryotic initiation factor 2alpha (eIF2alpha) endoplasmic reticulum (ER) stress response pathway on insulin mediated ER stress and hepatic and peripheral glucose metabolism. J. Biol. Chem. 2011, 286, 36163-36170. [CrossRef] [PubMed]

45. Dara, L.; Cheng, J.; Kaplowitz, N. The contribution of endoplasmic reticulum stress to liver diseases. Hepatology 2011, 53, 1752-1763. [CrossRef] [PubMed]

46. Adkins, Y.; Schie, I.W.; Fedor, D.; Reddy, A.; Nguyen, S.; Zhou, P.; Kelley, D.S.; Wu, J. A novel mouse model of nonalcoholic steatohepatitis with significant insulin resistance. Lab. Investig. 2013, 93, 1313-1322. [CrossRef] [PubMed]

47. Sinha, R.A.; You, S.H.; Zhou, J.; Siddique, M.M.; Bay, B.H.; Zhu, X.; Privalsky, M.L.; Cheng, S.Y.; Stevens, R.D.; Summers, S.A.; et al. Thyroid hormone stimulates hepatic lipid catabolism via activation of autophagy. J. Clin. Investig. 2012, 122, 2428-2438. [CrossRef] [PubMed] 
48. Gonzalez-Rodriguez, A.; Mayoral, R.; Agra, N.; Valdecantos, M.P.; Pardo, V.; Miquilena-Colina, M.E.; Vargas-Castrillón, J.; Lo Iacono, O.; Corazzari, M.; Fimia, G.M.; et al. Impaired autophagic flux is associated with increased endoplasmic reticulum stress during the development of NAFLD. Cell Death Dis. 2014, 5. [CrossRef]

49. Gong, L.L.; Li, G.R.; Zhang, W.; Liu, H.; Lv, Y.L.; Han, F.F.; Wan, Z.R.; Shi, M.B.; Liu, L.H. Akebia saponin D decreases hepatic steatosis through autophagy modulation. J. Pharmacol. Exp. Ther. 2016, 359, 392-400. [CrossRef]

50. Kabeya, Y.; Mizushima, N.; Ueno, T.; Yamamoto, A.; Kirisako, T.; Noda, T.; Kominami, E.; Ohsumi, Y.; Yoshimori, T. LC3, a mammalian homologue of yeast Apg8p, is localized in autophagosome membranes after processing. EMBO J. 2000, 19, 5720-5728. [CrossRef]

51. Papackova, Z.; Dankova, H.; Palenickova, E.; Kazdova, L.; Cahova, M. Effect of short- and long-term high-fat feeding on autophagy flux and lysosomal activity in rat liver. Physiol. Res. 2012, 61, S67-S76.

52. Shi, Y.; Jia, M.; Xu, L.; Fang, Z.; Wu, W.; Zhang, Q.; Chung, P.; Lin, Y.; Wang, S.; Zhang, Y. miR-96 and autophagy are involved in the beneficial effect of grape seed proanthocyanidins against high-fat-diet-induced dyslipidemia in mice. Phytother. Res. 2019, 33, 1222-1232. [CrossRef]

53. Zheng, Y.Y.; Wang, M.; Shu, X.B.; Zheng, P.Y.; Ji, G. Autophagy activation by Jiang Zhi Granule protects against metabolic stress-induced hepatocyte injury. World J. Gastroenterol. 2018, 24, 992-1003. [CrossRef]

54. Zhou, J.; Farah, B.L.; Sinha, R.A.; Wu, Y.; Singh, B.K.; Bay, B.H.; Yang, C.S.; Yen, P.M. Epigallocatechin-3-gallate (EGCG), a green tea polyphenol, stimulates hepatic autophagy and lipid clearance. PLoS ONE 2014, 9, e87161. [CrossRef] [PubMed]

55. Livak, K.J.; Schmittgen, T.D. Analysis of relative gene expression data using real-time quantitative PCR and the 2(-Delta Delta C(T)) method. Methods 2001, 25, 402-408. [CrossRef] [PubMed]

Sample Availability: Samples of the $\alpha$-linolenic acid-enriched cold-pressed perilla oil are available from the authors. 